\title{
Synthesis of Poly $(N, N$-dimethylacrylamide)/Silica Gel Polymer Hybrids by In Situ Polymerization Method
}

\author{
Ryo Tamaki, Kensuke NaKa, and Yoshiki Chujo* \\ Department of Polymer Chemistry, Graduate School of Engineering, \\ Kyoto University, Yoshida, Sakyo-ku, Kyoto 606-01, Japan
}

(Received July 3, 1997)

\begin{abstract}
As a novel synthetic method for organic inorganic polymer hybrids, in situ radical polymerization of vinyl monomers in sol-gel reaction of alkoxysilanes was investigated. $N, N$-Dimethylacrylamide (DMAAm) was polymerized simultaneously with hydrolysis and condensation of tetramethoxysilane (TMOS) to afford homogeneous poly $(N, N$ dimethylacrylamide) (PDMAAm) and silica gel polymer hybrids. Conversion of the monomer was supported by TGA, GPC and ${ }^{1} \mathrm{H},{ }^{13} \mathrm{C}$ NMR, which was found to have high value. It was made clear from nitrogen porosimetry study that homogeneity of the hybrids depends on the amount of acid catalyst and gelation degree of silica gels.

KEY WORDS Organic-Inorganic Polymer Hybrids / Sol-Gel Reaction / N,N-Dimethylacrylamide / Tetramethoxysilane / In Situ Polymerization Method /
\end{abstract}

Many organic and inorganic polymer hybrids have been synthesized in recent years by utilizing sol-gel method of alkoxysilanes. ${ }^{1,2}$ By combination of the two components, enhancement of mechanical strength of organic polymers with silica particles is possible. ${ }^{3-7}$ High transparency of hybrids is another important property of polymer hybrids and indispensable for developments of optical waveguides, ${ }^{8-12}$ optical biosensors, ${ }^{13}$ nonlinear optical materials, ${ }^{14,15}$ and other applications such as contact lenses. ${ }^{16}$ Hybrid materials are also potential candidates for catalysts, ${ }^{17-19}$ and gas separation membranes. ${ }^{20-24}$

The sol-gel technique of metal alkoxides is the most efficient means for the preparation of these composite materials. It comprises hydrolysis and subsequent condensation reaction of alkoxy- or hydroxysilanes (Scheme 1). ${ }^{25-29}$ When alkoxysilanes are used as precursors, $\mathrm{Si}-\mathrm{OH}$ groups are formed by hydrolysis of alkoxy groups and by condensation of the hydroxyl groups $\mathrm{Si}-\mathrm{O}-\mathrm{Si}$ linkage would be obtained. With further hydrolysis and condensation, a siloxane network develops via crosslinking of the oligomers. Xerogels are obtained after removal of solvents. One interesting property of the obtained silica gels is the presence of unreacted residual silanol groups after the gelation.

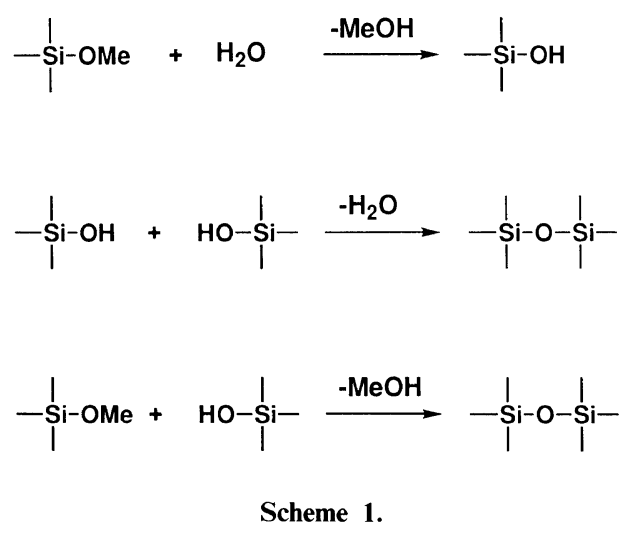

† To whom correspondence should be addressed.
To synthesize homogeneous polymer hybrids, organic polymers with functional groups that have specific interaction with silica gel are introduced into sol-gel reaction solution. ${ }^{16,30-43}$ Organic polymers such as poly(2-methyl-2-oxazoline), polyvinylpyrrolidone or poly $(N, N$-dimethylacrylamide) (PDMAAm) were incorporated homogeneously into the silica gel, utilizing hydrogen bonding interaction between the silanol groups and amide groups of organic polymers. ${ }^{4-54}$ These methods have some disadvantages in preparing homogeneous polymer hybrids when organic polymers have some bulky side groups in the vicinity of hydrogen bonding accepting groups or they lack functional groups that manifest strong interaction with silica gels. The method does not work well either when organic polymers themselves are hardly soluble in solvents used for the sol-gel reactions.

To overcome these problems, Novak ${ }^{2,36,55-57}$ and Schmidt ${ }^{16}$ proposed interesting methods for the preparation of organic-inorganic polymer hybrids from those polymers. These methods consist of the incorporation of monomers at the initial stage of a sol-gel reaction and following polymerization of the monomers simultaneously with the formation of silica gels. They utilized silane coupling agents in the reactions to introduce organic parts to the silica matrix. Modification would make these organic polymers covalently attached to the silica network and disperse the polymers in the silica gels homogeneously.

We consider in the following paragraphs a novel method for synthesis of organic-inorganic polymer hybrids. We used in situ radical polymerization of vinyl monomers in a sol-gel reaction and found that the hydrogen bonding interaction and/or physical entrapment of monomers in the silica matrix are strong enough to afford homogeneous polymer hybrids. Vinyl monomers are initially introduced to sol-gel reaction mixtures and then subjected to polymerization by radical initiators. Here $N, N$-dimethylacrylamide (DMAAm) was used as an organic monomer. 


\section{EXPERIMENTAL}

General Procedures

${ }^{1} \mathrm{H}$ NMR spectra were measured on JEOL EX270 spectrometer with chloroform- $d$. IR spectra were recorded on Perkin-Elmer 1600 Series FT-IR. Thermogravimetric analyses were measured on Shimadzu TG30 , TGC-30 at the rate of $10^{\circ} \mathrm{C} \mathrm{min}^{-1}$ in air. Nitrogen absorption porosimetry was conducted with BEL JAPAN INC. The reactions were carried out in air unless otherwise mentioned. GPC analysis was conducted with HLC-8020 (Tosoh), SPD6AV (Shimadzu) with TSKgel $\mathrm{GMH}_{\mathrm{HR}}-\mathrm{H}$ column.

\section{Materials}

All solvents and reagents were used as supplied except the following. Methanol was distilled with sodium under nitrogen. DMAAm was distilled under nitrogen in vacuo. Azobisisobutyronitrile (AIBN) was recrystallized in ethanol at $35^{\circ} \mathrm{C}$. TMOS was distilled under nitrogen.

\section{Poly( $N, N$-dimethylacrylamide $)$ and Silica Hybrids}

DMAAm (1.0 g) and AIBN were dissolved in $20 \mathrm{ml}$ methanol in a capped $50 \mathrm{ml}$ glass sample-flask, followed by the addition of tetramethoxysilane (TMOS) $(2.0 \mathrm{~g})$ and $0.1 \mathrm{~N} \mathrm{HCl}$. After being stirred at room temperature for a certain period of time, the mixuture was heated at $60^{\circ} \mathrm{C}$ in an oven for 2 weeks in an open flask, letting the solvent evaporate. The obtained dried gel was crushed into powder for further analysis.

\section{Soxhlet Extraction}

The powdered hybrids were put in cellulose timbers and extracted with methanol for 3 days in a Soxhlet extraction apparatus.

\section{Nitrogen Absorption Porosimetry}

The powder of the hybrid was heated at $600^{\circ} \mathrm{C}$ under ambient atmosphere to remove organic parts. The sample was then dried at $200^{\circ} \mathrm{C}$ for $2 \mathrm{~h}$ at reduced pressure under nitrogen atmosphere. Surface area was calculated with the BET equation in the range of 0.05 to $0.30\left(p / p_{0}\right)$ and the pore size distribution was calculated by $\mathrm{BJH}$ method. ${ }^{58,59}$

\section{RESULTS AND DISCUSSION}

Preparation of Poly $(N, N$-dimethylacrylamide) Hybrids

The polymer hybrids were prepared as illustrated in Scheme 2. DMAAm was added as a starting material to a sol-gel reaction mixture of TMOS with AIBN as the radical initiator. The sol-gel reaction was catalyzed by an acid catalyst to give silica gel. Therefore, it was expected that organic and inorganic polymerization would proceed simultaneously when the mixture was
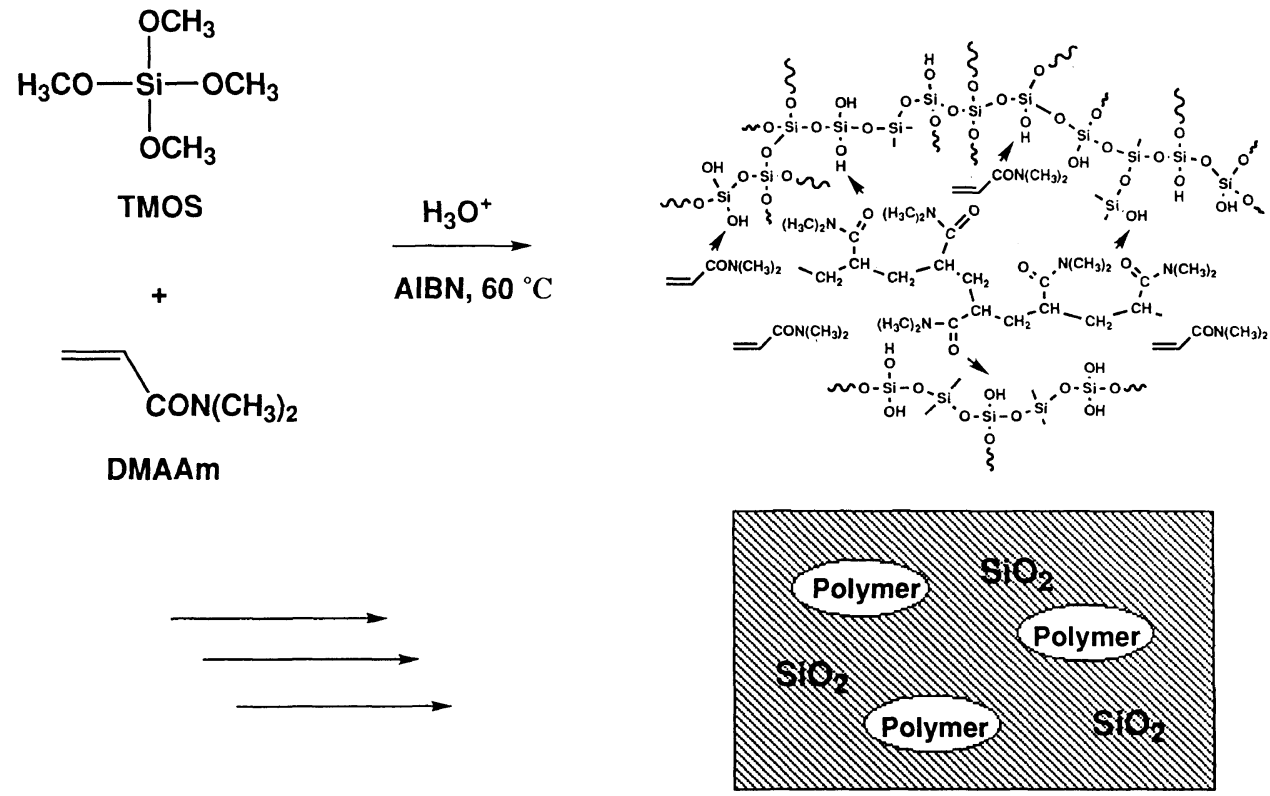

Scheme 2 .

Table I. Preparation of poly(dimethylacrylamide) hybrid ${ }^{\mathrm{a}}$

\begin{tabular}{|c|c|c|c|c|c|c|c|c|}
\hline \multirow{2}{*}{ Run } & \multirow{2}{*}{$\begin{array}{l}\text { Molar ratio } \\
\text { of AIBN/ } \\
\text { DMAAm }\end{array}$} & \multirow{2}{*}{ Appearance } & \multirow{2}{*}{$\frac{\text { Weight loss }^{\mathbf{b}}}{\%}$} & \multicolumn{2}{|c|}{ Conversion $/ \%$} & \multirow{2}{*}{$\begin{array}{r}M_{n} \mathrm{e}^{\mathrm{e}} \\
\times 10^{-4}\end{array}$} & \multirow{2}{*}{$\begin{array}{c}M_{w}{ }^{\mathrm{e}} \\
\times 10^{-4}\end{array}$} & \multirow{2}{*}{$M_{w} / M_{n}$} \\
\hline & & & & $\mathrm{TGA}^{\mathrm{c}}$ & $\mathrm{GPC}^{\mathrm{d}}$ & & & \\
\hline 1 & 0 & Transparent & 51.9 & 0 & 0 & - & - & - \\
\hline 2 & 0.001 & Transparent & 51.5 & $\sim 0$ & 12.9 & 1.3 & 2.3 & 1.8 \\
\hline 3 & 0.01 & Transparent & 54.9 & $>90$ & 94.2 & 3.1 & 7.6 & 2.5 \\
\hline 4 & 0.1 & Transparent & 57.6 & 81.7 & 95.7 & 0.4 & 1.3 & 2.9 \\
\hline
\end{tabular}

${ }^{\text {a }}$ Conditions: weight ratio of DMAAm/TMOS $=1 / 2 . \mathrm{TMOS}=2.0 \mathrm{~g} . \mathrm{MeOH}=20 \mathrm{ml} .0 .1 \mathrm{~N} \mathrm{HCl}=0.40 \mathrm{ml} . \quad{ }^{\mathrm{b}}$ Calculated by TGA. ${ }^{\mathrm{c}}$ Weight $\%$ of polymer in total weight loss. ${ }^{\mathrm{d}}$ Area ratio of the polymer. ${ }^{\mathrm{e}}$ Calculated by GPC. 


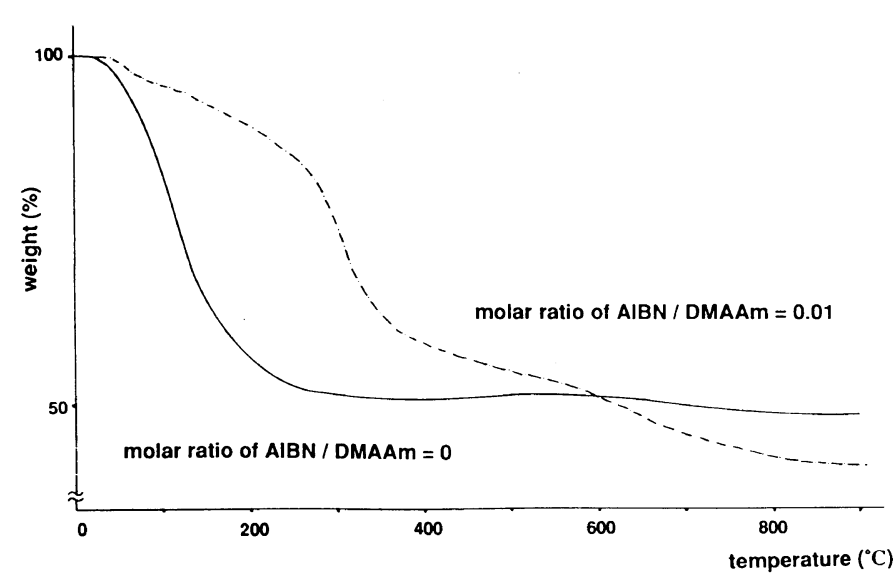

Figure 1. TGA trace of PDMAAm hybrids.

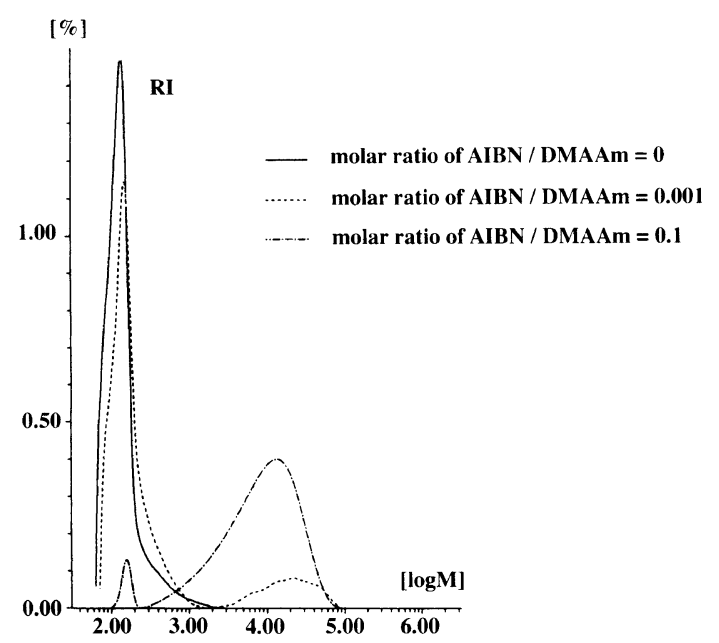

Figure 2. GPC chart of PDMAAm extracted from hybrid.

heated at $60^{\circ} \mathrm{C}$. Content of AIBN was varied from 0 to 0.10 equivalent to the monomer and effects of the initiator content on the conversion of the monomer were evaluated.

Thermogravimetric analysis (TGA) is a good method for calculating conversion of the monomer in the hybrids. As shown in Figure 1, without AIBN, the organic part started decomposition below $100^{\circ} \mathrm{C}$ and reached equilibrium before $200^{\circ} \mathrm{C}$. This implies the monomer did not polymerize. The onset of decomposition temperature shifted to $300^{\circ} \mathrm{C}$ with increase of AIBN contents which is fully consistent with the formation of PDMAAm. Conversion was calculated by dividing the wt $\%$ of the polymer part by the whole weight loss. The value for each hybrid is shown in Table I.

We utilized gel permeation chromatography (GPC) to confirm the above results. The polymers were extracted from the silica gel by a Soxhlet apparatus with methanol and subjected to GPC analysis. Areas of the remaining monomer and the polymer in GPC charts were found comparable to the conversion values calculated from TGA. The spectrum of the system without an initiator showed a large portion of peak at a low molecular weight. In contrast, the peak decreased by increasing the initiator. In the system with $10 \%$ of the initiator, for example, this peak almost disappeared while the peak at higher molecular weight intensified (Figure 2).

Molecular weights for the extracted polymers are also

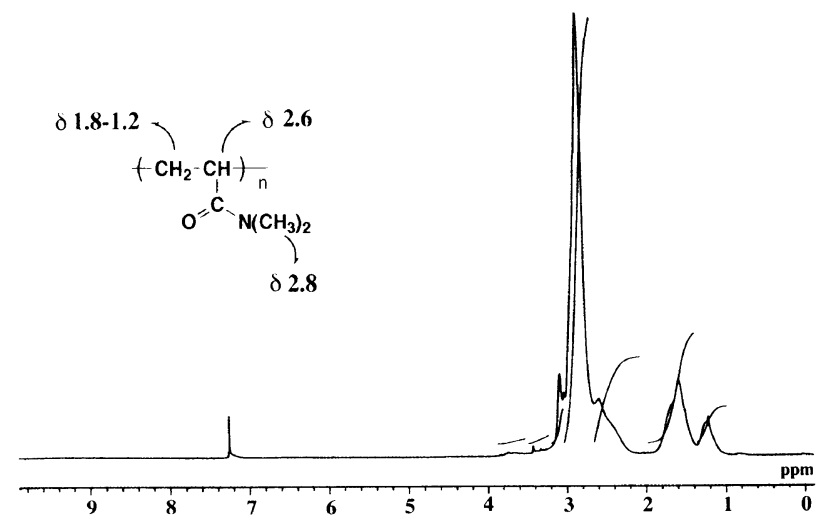

Figure 3a. $\quad{ }^{1} \mathrm{H}$ NMR spectrum of PDMAAm extracted from hybrid.

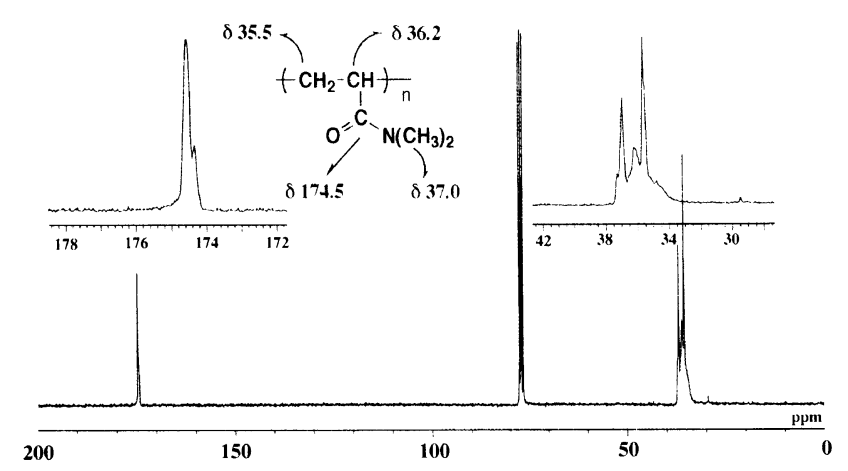

Figure 3b. ${ }^{13} \mathrm{C}$ NMR spectrum of PDMAAm extracted from hybrid.

shown in Table I. The polymer obtained with $1 \%$ AIBN was found to have a fairly high weight-average molecular weight of 76000 . The polymer with initial AIBN content of $0.1 \%$ had that of 23000 . The low molecular weight could be the result of insufficient conversion of the monomer. Although high conversion was obtained, the molecular weight decreased when $10 \%$ of AIBN was used, which could be explained kinetically as observed in normal radical polymerization.

${ }^{1} \mathrm{H}$ and ${ }^{13} \mathrm{C}$ NMR charts of the extracted polymer are shown in Figures $3 \mathrm{a}$ and $3 \mathrm{~b}$. In ${ }^{1} \mathrm{H}$ NMR spectrum, the peaks of methyl, methyne, and methylene can be observed at $2.8,2.6$, and $1.8-1.2 \mathrm{ppm}$, respectively, while the peaks of the olefin groups disappeared. In the ${ }^{13} \mathrm{C}$ NMR spectrum, a peak of the carbonyl group was observed at $174.5 \mathrm{ppm}$ and that of methyl, methyne, and methylene carbons at $37.0,36.2$, and $35.5 \mathrm{ppm}$, respectively. All these results support the effective conversion of the monomer in the sol-gel reaction mixture.

The polymer hybrids were found to be homogeneous and transparent. The homogeneity of the hybrids were assumed due to the strong interaction between the polymer and silica gel. As reported previously, carbonyl groups of PDMAAm were supposed to interact with the residual silanol groups. This would allow the polymer disperse in silica gels homogeneously. ${ }^{44,46-51,53,54}$ The interaction was evaluated by FT-IR. As shown in Figure 4, stretching vibration peak of the carbonyl group of PDMAAm shifted from $1638 \mathrm{~cm}^{-1}$ to lower wavenumber field at $1625 \mathrm{~cm}^{-1}$, which is evidence of hydrogen bonding interaction. The same was observed in a composite of silica gel and DMAAm monomer prepared by the same method described above but without the radical initiator. The stretching vibration peak of the 


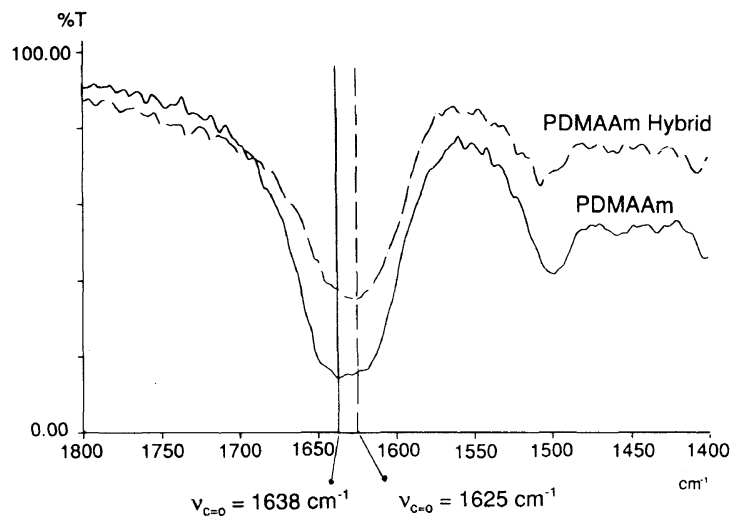

Figure 4. FT-IR Spectra of PDMAAm and PDMAAm hybrid
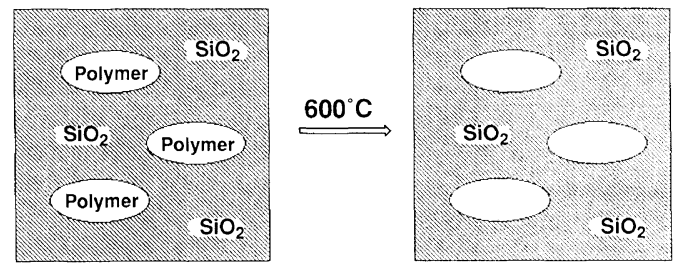

Figure 5. Formation of porous silica gel from a polymer hybrid.

carbonyl group shifted from $1651 \mathrm{~cm}^{-1}$ to $1642 \mathrm{~cm}^{-1}$ in this case. These results indicate that the monomer initially dispersed in the forming silica gel homogeneously by hydrogen bonding interaction, resulting in uniform dispersion of PDMAAm in the silica matrix with accomplishment of the sol-gel reaction.

\section{Effects of Acid Catalyst Content on Homogeneity}

A study of the effects of catalyst contents on the homogeneity of the polymer hybrids is discussed here. Catalysts content was altered from $0.02 \mathrm{ml}$ to $1.6 \mathrm{ml}$. Homogeneity was evaluated by nitrogen porosimetry study. As reported in early studies, dispersity of organic polymers inside polymer hybrids can be determined by measuring pore size distribution of porous silica gels obtained by charring the polymer hybrids at $600^{\circ} \mathrm{C} .{ }^{54,60}$ Initially the hybrids were charred in an oven at $600^{\circ} \mathrm{C}$ for $24 \mathrm{~h}$, by which the organic elements were completely removed from the hybrids, leaving porous silica gel (Figure 5). The siloxane lattice is so rigid that it would not be affected by this temperature. ${ }^{60}$ Therefore, the size of the pores was expected to be comparable to the size of organic polymer domain in the original hybrids, as was confirmed for dendrimer polymer hybrids. ${ }^{54}$ The porous silicas were subjected to nitrogen sorption porosimetry study. Surface areas and pore volumes of the porous silicas were obtained by the BET method using the obtained isotherm curve. ${ }^{59}$

As shown in Table II, surface area and pore volume of porous silica increased with acid catalyst. The porous silica prepared from the polymer hybrid in run 1 had pore volume of $43.2 \mathrm{mlg}^{-1}$ and surface area of $188 \mathrm{~m}^{2} \mathrm{~g}^{-1}$, while the porous silica obtained from the polymer hybrid in run 2 had values of $83.9 \mathrm{mlg}^{-1}$ for pore volume and $365 \mathrm{~m}^{2} \mathrm{~g}^{-1}$ for surface area. PDMAAm is thus dispersed more homogeneously in the polymer hybrid prepared with a larger acid catalyst content.

Dispersity was also confirmed by measuring pore size
Table II. Preparation of poly(dimethylacrylamide) hybrid ${ }^{\mathrm{a}}$

\begin{tabular}{|c|c|c|c|c|}
\hline \multirow{2}{*}{ Run } & $0.1 N \mathrm{HCl}$ & Pore volume ${ }^{b}$ & Surface area $^{\mathrm{b}}$ & \multirow{2}{*}{$\frac{\text { Pore radius }^{\mathrm{c}}}{\mathrm{nm}}$} \\
\hline & $\mathrm{ml}$ & $\mathrm{mlg}^{-1}$ & $\mathrm{~m}^{2} \mathrm{~g}^{-1}$ & \\
\hline 1 & 0.02 & 43.19 & 188.0 & $-^{d}$ \\
\hline 2 & 1.60 & 83.86 & 365.0 & 1.9 \\
\hline
\end{tabular}

${ }^{a}$ Conditions: weight ratio of DMAAm $/$ TMOS $=1 / 2$. TMOS $=2.0 \mathrm{~g}$. $\mathrm{MeOH}=20 \mathrm{ml}$. Molar ratio of AIBN/DMAAm $=1 / 100$. ${ }^{\mathrm{b}}$ Calculated by BET method. ${ }^{\mathrm{c}}$ Calculated by BJH method. ${ }^{\mathrm{d}}$ No peak was observed at $0-30 \mathrm{~nm}$.

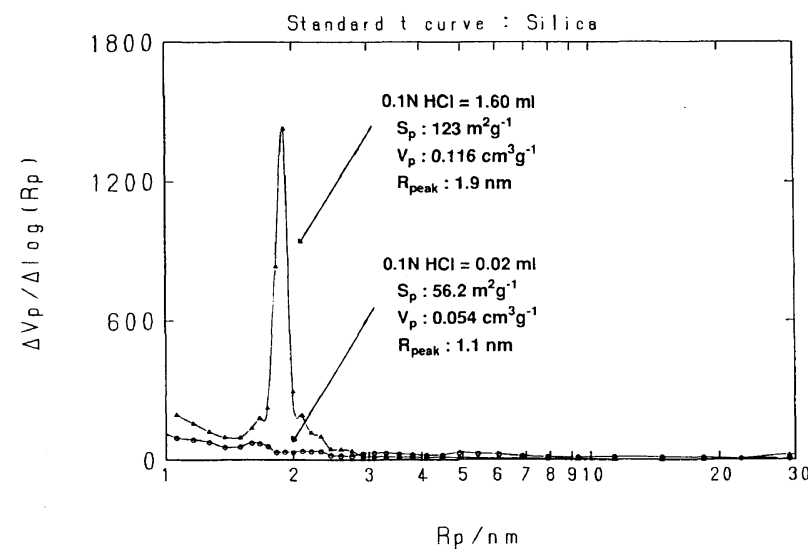

Figure 6. Pore size distribution plot of porous silica obtained from PDMAAm hybrid.

of the porous silicas. The pore size was calculated by the $\mathrm{BJH}$ method $^{59}$ from the desorption isotherm curve obtained by nitrogen absorption porosimetry of the porous silicas. The results are illustrated in Figure 6 and Table II. The porous silica obtained from the polymer hybrid of run 2 exhibited sharp distribution at $1.9 \mathrm{~nm}$ suggesting molecular-level dispersion of the polymer inside the silica gel. In contrast, the porous silica obtained from the polymer hybrid in run 1 did not show a noticeable peak. Considering the result of the surface area and volume study, the polymer was suspected to aggregate to form domains larger than $30 \mathrm{~nm}$.

Improvement of homogeneity of the hybrids could be explained by the increased sol-gel reaction rate. The rate of reaction increases with acid content. ${ }^{27,61,62}$ It is expected that organic polymers are trapped inside the silica matrix before they aggregate and give more uniform polymer hybrids when silica matrix is formed promptly. A branched siloxane polymer would be formed resulting in three dimensional silica matrix with water content more than 5 equivalent to alkoxysilanes. ${ }^{63-65}$ The morphological change of siloxane structure might contribute to increasing interface of two elements that would lead to homogeneous dispersion of the polymer inside the silica matrix.

\section{Effects of Gelation Degree of Silica Gels on the Homo- geneity}

Gelation degree of the silica gels had significant effect on homogeneity of the polymer hybrids. The reaction mixture containing all reagents was kept stirred at room temperature for a different period of time before initiating the radical polymerization. Although gelation of TMOS 


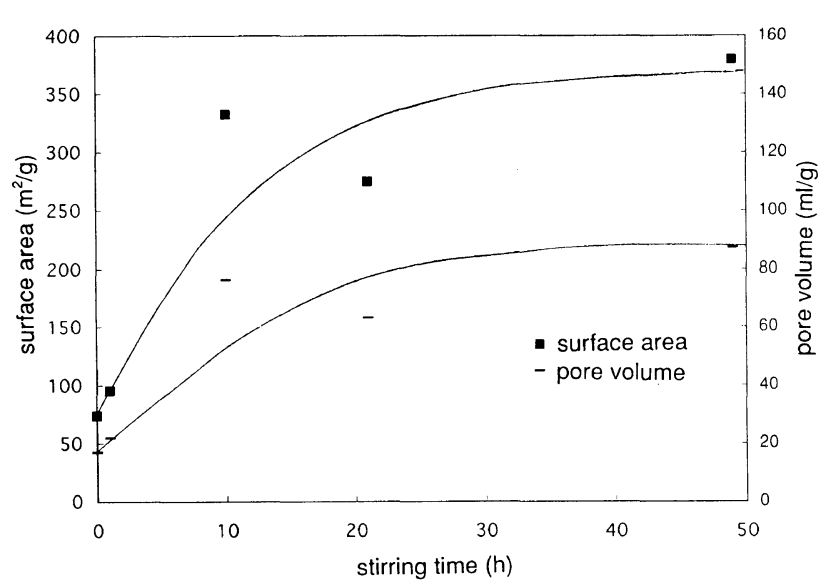

Figure 7. Surface area and pore volume of porous silica obtained from PDMAAm hybrid.

would proceed during stirring, the polymerization of DMAAm is suppressed at this temperature. Therefore, gelation of silica matrix at the moment of polymerization of DMAAm could be controlled by varying the period of stirring time.

Effects of the stirring time on homogeneity were obvious, especially in the period between 0 to $10 \mathrm{~h}$ (Figure 7). While the silica obtained from the hybrid without stirring had little pore volume and surface area, both increased with extension of stirring time to yield values of $76 \mathrm{ml} \mathrm{g}^{-1}$ for pore volume and $332 \mathrm{~m}^{2} \mathrm{~g}^{-1}$ for surface area after $10 \mathrm{~h}$. The results demonstrate that homogeneity is improved by extending the stirring time, i.e., the gelation degree of silica gels. It is assumed that the silica matrix grows enough after $10 \mathrm{~h}$ stirring time and the polymerization takes place inside the formed silica cage. As such, aggregation of the polymer were suppressed to form uniform hybrids.

Combining the results with those of the acid content effect, it seems reasonable to say that the physical entrapment of the monomer plays a critical role in producing homogeneous polymer hybrids as well as the hydrogen bonding interaction, particularly in this "in situ polymerization method."

\section{CONCLUSION}

It was confirmed that the simultaneous radical polymerization of DMAAm with hydrolysis and condensation of TMOS produces highly homogeneous PDMAAm and silica gel hybrids. In situ polymerization of DMAAm proceeded effectively to afford PDMAAm of high molecular weight. Homogeneity of the hybrids depends on amount of acid catalyst and gelation degree of silica gels, which indicates the critical role of physical entrapment of the polymer in forming silica gels as well as the hydrogen bonding interaction for uniform dispersion of the polymer. This method seems more advantageous with respect to versatility than the prepolymer incorporation methods. At the same time, it dose not require modification of organic monomers to obtain homogeneous polymer hybrids. Thus the number of processes for the preparation is reduced. This method should prove useful for the synthesis of polymer hybrids starting from organic polymers without high affinity to silica gels, since the aggregation may be suppressed if the monomer polymerizes in the "cage" of the silica matrix. Based on this idea, homogeneous polystyrene and silica gel polymer hybrids were prepared. ${ }^{66}$

\section{REFERENCES}

1. J. Wen and G. L. Wilkes, Chem. Mater., 8(8), 1667 (1996).

2. B. M. Novak, Adv. Mater., 5, 422 (1993).

3. G. S. Sur and J. E. Mark, Eur. Polym. J., 21, 1051 (1985).

4. J. E. Mark and G. S. Sur, Polym. Bull., 14, 325 (1985).

5. S. J. Clarson and J. E. Mark, Polym. Commun., 28, 249 (1987).

6. C.-C. Sun and J. E. Mark, Polymer, 30, 104 (1989).

7. J. E. Mark, Chemtech., April, 230 (1989).

8. C. J. Wung, Y. Pang, P. N. Prassad, and F. E. Karasz, Polymer, 32, 605 (1991).

9. S. Motakef, T. Suratwala, R. L. Roncone, J. M. Boulton, G. Teowee, G. F. Neilson, and D. R. Uhlmann, J. Non-Cryst. Solids, 178, 31 (1994).

10. S. Motakef, T. Suratwala, R. L. Roncone, J. M. Boulton, G. Teowee, and D. R. Uhlmann, J. Non-Cryst. Solids, 178, 37 (1994)

11. M. Yoshida and P. N. Prassad, Applied Optics, 35, 1500 (1996).

12. C. Xu, L. Eldada, C. Wu, R. A. Norwood, L. W. Shacklette, J. T. Yardley, and Y. Wei, Chem. Mater., 8, 2701 (1996).

13. B. C. Dave, B. Dunn, J. S. Valentine, and J. I. Zink, Anal. Chem., 66, 1120 (1994).

14. C. Claude, B. Garetz, Y. Okamoto, and S. Tripathy, Mater. Lett., 14, 336 (1992)

15. B. L-Davies, M. Samoc, and M. Woodruff, Chem. Mater., 8, 2586 (1996).

16. G. Philipp and H. Schmidt, J. Non-Cryst. Solids, 63, 283 (1984).

17. M. T. Reetz, A. Zonta, and J. Simpelkamp, Angew. Chem. Int. Ed. Engl., 34, 301 (1995).

18. M. A. Harmer, W. E. Farneth, and Q. Sun, J. Am. Chem. Soc., 118, 7708 (1996).

19. U. Schubert, New J. Chem., 18, 1049 (1994).

20. S. P. Nunes, J. Schultz, and K.-V. Peinemann, J. Mater. Sci. Lett., 15, 1139 (1996)

21. M. Smaihi, T. Jermoumi, J. Marignan, and R. D. Noble, $J$. Membrane Sci., 116(2), 211 (1996).

22. R. Tamaki, Y. Chujo, T. Yazawa, and K. Kuraoka, Polym. Prepr., Jpn., 44, 973 (1995).

23. J. Marchese, N. Ochoa, and C. Pagliero, J. Chem. Tech. Biotechnol., 63, 329 (1995).

24. C. Guizard and P. Lacan, New J. Chem., 18, 1097 (1994).

25. H. Schmidt, H. Scholze, and A. Kaiser, J. Non-Cryst. Solids, 63, 1 (1984).

26. C. J. Brinker, K. D. Keefer, D. W. Schaefer, R. A. Assink, B D. Kay, and C. S. Ashley, J. Non-Cryst. Solids, 63, 45 (1984).

27. F. Orgaz and H. Rawson, J. Non-Cryst. Solids, 82, 57 (1986).

28. C. J. Brinker and G. W. Scherer, J. Non-Cryst. Solids, 70, 301 (1985).

29. C. J. Brinker and G. W. Scherer, "Sol-Gel Science," Harcourt Brace \& Co., Publishers, Boston, MA, 1990.

30. J. L. W. Nell, G. L. Wilkes, and D. K. Mohanty, J. Appl. Polym. Sci., 40, 1177 (1990).

31. H. Schmidt, J. Non-Cryst. Solids, 178, 302 (1994).

32. Y. Wei, R. Bakthavatchalam, D. Yang, and C. K. Whitecar, Polym. Prepr., Am. Chem. Soc., Div. Polym. Chem., 32, 503 (1991).

33. Y. Wei, W. Wang, J.-M. Yeh, B. Wang, D. Yang, and J. K. Murray Jr., Adv. Mater., 6, 372 (1994).

34. Y. Wei, D. Yang, L. Tang, and M. K. Hutchins, J. Mater. Res., 8, 1143 (1993).

35. Y. Wei, J.-M. Yeh, D. Jin, X. Jia, and J. Wang, Chem. Mater., 7, 969 (1995).

36. M. W. Ellsworth and B. M. Novak, J. Am. Chem. Soc., 113, 2756 (1991).

37. B. K. Coltrain, W. T. Ferrar, C. J. T. Landry, T. R. Molaire, and N. Zumbulyadis, Chem. Mater., 4, 358 (1992).

38. J. J. Fitzgerald, C. J. T. Landry, and J. M. Pochan, Macromolecules, 25, 3715 (1992).

39. C. J. T. Landry, B. K. Coltrain, and B. K. Brady, Polymer, 33, 1486 (1992). 
40. C. J. T. Landry, B. K. Coltrain, J. A. Wesson, N. Zumbylyadis, and J. L. Lippert, Polymer, 33, 1496 (1992).

41. C. J. T. Landry, B. K. Coltrain, M. R. Landry, J. J. Fitzgerald, and V. K. Long, Macromolecules, 26, 3702 (1993).

42. C. J. T. Landry and B. B. K. Coltrain, J. Macromol. Sci.-Pure Appl. Chem., A31(12), 1965 (1994).

43. K. G. Sharp, Hybrid Organic-Inorganic Composites, 163 (1995).

44. Y. Chujo, E. Ihara, S. Kure, and T. Saegusa, Macromolecules, 26, 5681 (1993).

45. M. Toki, T. Y. Chow, T. Ohnaka, H. Samura, and T. Saegusa, Polym. Bull., 29, 653 (1992).

46. T. Saegusa and Y. Chujo, J. Macromol. Sci.-Chem., A27, 1603 (1990).

47. Y. Chujo and T. Saegusa, Adv. Polym. Sci., 100, 11 (1992).

48. Y. Chujo, J. Thermo. Plastics, Japan, 16, 99 (1995).

49. Y. Chujo, E. Ihara, S. Kure, N. Suzuki, and T. Saegusa, Makromol. Chem., Macromol. Symp., 42/43, 303 (1991)

50. Y. Chujo, "Organic/Inorganic Polymer Hybrids," Vol. 6, CRC Press, Boca Raton, FL, 1996, p 4793.

51. Y. Chujo, Polym. Mater. Sci. Eng., 74, 65 (1996).

52. T. Saegusa and Y. Chujo, Makromol. Chem., Macromol. Symp., 51, 1 (1991).

53. T. Saegusa and Y. Chujo, Makromol. Chem., Macromol. Symp.,
64, 1 (1992).

54. Y. Chujo, H. Matsuki, S. Kure, T. Saegusa, and T. Yazawa, J. Chem. Soc., Chem. Commun., 635 (1994)

55. C. L. Jackson, B. J. Bauer, A. I. Nakatani, and J. D. Barnes, Chem. Mater., 8, 727 (1996).

56. B. M. Novak, Polym. Prepr., Am. Chem. Soc., Div. Polym. Chem., 32, 530 (1990).

57. B. M. Novak, Macromolecules, 24, 5481 (1991).

58. S. Kondo, T. Ishikawa, and I. Abe, "Science of Adsorption (Kyutyaku no Kagaku)," 1st ed, Maruzen, Tokyo, 1991, p 228

59. S. J. Gregg and K. S. W. Sing, "Adsoption, Surface Area and Porosity," 2nd ed, New York, N. Y., 1982.

60. D. A. Loy and K. J. Shea, Chem. Rev., 95, 1431 (1995).

61. L. W. Kelts, N. J. Ejjinger, and S. M. Melpolder, J. Non-Cryst. Solids, 83, 353 (1986).

62. T. W. Zerda, I. Artaki, and J. Jonas, J. Non-Cryst. Solids, 81, 365 (1986).

63. M. Yamane, S. Inoue, and A. Yasumori, J. Non-Cryst. Solids, 63, 13 (1984)

64. S. Sakka and H. Kozuka, J. Non-Cryst. Solids, 100, 142 (1988).

65. S. Sakka, K. Kamiya, K. Makita, and Y. Yamamoto, J. NonCryst. Solids, 63, 223 (1984).

66. R. Tamaki, K. Naka, and Y. Chujo, Polym. Bull., 39, 303 (1997). 